\title{
The simple view of second language reading throughout the primary grades
}

\author{
Ludo Verhoeven · Jan van Leeuwe
}

Published online: 18 November 2011

(C) The Author(s) 2011. This article is published with open access at Springerlink.com

\begin{abstract}
In the Simple View of Reading proposed by Hoover and Gough (1990), reading comprehension is conceived as the product of word decoding and listening comprehension. It is claimed that listening comprehension or the linguistic processes involved in the comprehension of oral language strongly constrain the process of reading comprehension. In several studies, evidence for this theoretical framework has been provided for first language learners. In the present study, an attempt was made to find empirical evidence for the same view underlying second language reading. Therefore, the word decoding and listening comprehension skills of samples of 1,293 first language (L1) learners and 394 second language (L2) learners of Dutch were related to their reading comprehension abilities throughout the primary grades. It was found that the levels of word decoding were more or less equal in the two groups of learners, whereas the L2 learners stayed behind their first L1 peers in both listening, and reading comprehension. The relationships between word decoding, listening comprehension and reading comprehension turned out to be highly comparable. A longitudinal analysis of data showed the Simple View of Reading to be equally valid for L1 and L2 learners. With progression of grade, the impact of word decoding on reading comprehension decreased, whereas the impact of listening comprehension showed an increase to the same extent in the two groups of learners. However, the reciprocity of the relationship between listening comprehension and reading comprehension tended to be less prominent in the group of L2 learners.
\end{abstract}

Keywords Second language reading - Simple view · Listening comprehension . Word decoding $\cdot$ Reading comprehension

L. Verhoeven $(\bowtie) \cdot$ J. van Leeuwe

Behavioural Science Institute, Faculty of Social Sciences, Radboud University Nijmegen,

P.O. Box 9044, 6500 KD Nijmegen, The Netherlands

e-mail: L.Verhoeven@pwo.ru.nl 


\section{Introduction}

In the Simple View of Reading proposed by Hoover and Gough (1990), reading comprehension is defined as the product of word decoding and listening comprehension. More specifically, it is claimed that listening comprehension or the linguistic processes involved in the comprehension of oral language strongly constrain the process of reading comprehension or, in other words, the identification of word meanings, the representation of sentences, the drawing of inferences, and the identification of underlying text structure (text model) and the global gist of a text (situation model) (see Perfetti, Landi, \& Oakhill, 2005; Verhoeven \& Perfetti, 2008). In several studies, part of the evidence for this theoretical framework has been provided. Word decoding or the accurate and fast retrieval of the phonological code for written word forms has proved to be essential for the development of reading comprehension. Automated word recognition frees mental resources for closer consideration of the meaning of a text and thereby allows readers to employ reading as a tool for the acquisition of new information and knowledge (National Reading Panel, 2000; Perfetti, 1998).

Besides word decoding, listening comprehension turns out to be an important predictor of reading comprehension. Research showed younger and poorer readers to have more problems with these processes in listening comprehension than older and better readers (e.g., Cain \& Oakhill, 1998; Yuill \& Oakhill, 1991). In a longitudinal study, Vauras, Kinnunen, and Kuusela (1994) examined the development of text processing skills in third to fifth grade children. They found that young children tend to process text in a linear, element by element fashion and that higher level processing skills are increasingly utilized with age. The specific developmental patterns were dependent on the initial listening comprehension achievement level of a child. Average and high achievers made clear progress, while low achieving children showed little or only slow progression. Other studies testing the so-called Simple View of Reading also provide insight into the interaction between decoding and listening comprehension in beginning as opposed to proficient readers. These studies consistently show the role of decoding in the explanation of reading comprehension to be large for beginning readers and the role of listening comprehension to become more prominent for more proficient readers (e.g., Bast \& Reitsma, 1998; Carver, 1993; Chen \& Vellutino, 1997; Juel, 1988; Tunmer \& Hoover, 1993). However, it might well be the case that the relationship between listening comprehension and reading comprehension is reciprocal since both originate from the same basic linguistic competence, including phonological, lexical, grammatical and textual abilities (cf. Sears \& Keogh, 1993).

Although L2 reading processes may be impeded for various reasons (cf. Verhoeven, 2010), the results of recent surveys by Verhoeven (2000) and Siegel (2003) show the development of word decoding skills of L1 and L2 learners in the long run to develop at more or less equal rates. This may be due to the fact that during the process of learning to read many of the L2 learners succeed in acquiring essentials of the target language in the domains of phonology and orthography. The positive results of L2 learners in word decoding may also be attributed to cross-language transfer. It has indeed been found that positive transfer or overlap with L1 at the level 
of phonology (Ellis \& Schmidt, 1997; Lopez \& Greenfield, 2004; Lindsey, Manis, \& Bailey, 2003) and orthography (Deacon, Wade-Woolley, \& Kirby, 2009; Geva \& Siegel, 2000) may help the L2 learners in building up word decoding skills in the L2.

However, a limited oral proficiency level may make the development of reading comprehension for L2 learners at risk (see Genesee, Lindholm-Leary, Saunders, \& Christian, 2006). Estimates of oral vocabulary knowledge have revealed major differences between L2 and L1 learners, and the smaller L2 vocabularies of secondlanguage learners may therefore seriously impede their L2 reading (Verhoeven, 2000). Furthermore, the semantic networks of L2 learners appear to be less tight than those of L1 learners. That is, L2 learners not only have less extensive vocabularies than L1 learners but also fewer associative links between words (Vermeer, 2001). L2 learners may also experience difficulties in reading comprehension due to problems in sentence comprehension (cf. Bernhardt, 2005). The limited syntactic sensitivities of young and less experienced readers make the discovery of the structures underlying sentences a particularly difficult task and may therefore create problems with reading comprehension at times (cf. Goldman, 2003). Along these lines, Verhoeven (1990) has found the morphosyntactic knowledge of L2 learners to significantly predict their L2 reading comprehension by the end of second grade. From studies with more advanced learners, moreover, limited syntactic knowledge and a basic unawareness of syntactic boundaries has also been found to hamper the L2 reading process (Kitajima, 1997).

A full account of the Simple View of Reading in relation to both L1 and L2 language learners was given by Droop and Verhoeven (2003) in a study with children learning to read in Dutch as L1 and L2, living in The Netherlands. The authors studied the development and interrelations of reading comprehension, word decoding, and oral language skills of high and low SES Dutch and low SES minority children with a Turkish and Moroccan background in the third and fourth grades of primary school in The Netherlands. Several tests to measure reading comprehension, word decoding, oral text comprehension, morphosyntactic knowledge, and vocabulary knowledge were administered at the beginning of third grade, the end of third grade, and the end of fourth grade. With respect to interrelations between oral language and reading, it was found that for both L1 and L2 learners the development of reading comprehension tends to be influenced more by top-down comprehensionbased processes than bottom-up word-decoding processes. Relative to the Dutch children, however, for the minority children, the role of oral Dutch appears to be more prominent in the explanation of the variation in reading comprehension.

In a similar vein, Proctor, Carlo, August, and Snow (2005) tested the relationship between word decoding and oral proficiency, on the one hand, and reading comprehension, on the other hand, in Spanish speaking English language learners. English decoding measures included alphabetic knowledge and fluency. English oral language measures included vocabulary and listening comprehension. The results showed decoding to play a less predictive role than oral proficiency. L2 listening comprehension made an independent, proximal contribution to L2 reading comprehension, whereas L2 vocabulary assumed both proximal and distant relationships with L2 reading comprehension. Like the previous study, the data showed that L2 oral language proficiency-particularly L2 vocabulary knowledge — can be seen as the crucial predictor of L2 reading comprehension. 
From the research conducted so far, it can be concluded that the Simple View of Reading provides an explanatory framework not only for reading comprehension in the native language, but also for L2 reading comprehension. However, a developmental perspective over the primary grades is generally lacking. It is by no means clear how word decoding and oral language proficiency in L1 versus L2 reading relate in the early, intermediate, and upper grades. In most of the studies concerned with individual variation in children's reading comprehension to date, a longitudinal approach has not been adopted. In only a very few studies, moreover, has an attempt been made to examine the interaction between bottom-up word recognition processes and top-down processes requiring the use of word knowledge and other linguistic skills in relation to the development of reading comprehension. Insofar as the relations between various linguistic skills and children's reading comprehension have been explored, the data are typically cross-sectional or only involve one or two grades.

Therefore, in the present study, a longitudinal perspective was taken to examine the relationship between word decoding, listening comprehension, and reading comprehension among a representative samples of elementary school children learning to read Dutch as L1 or L2. In The Netherlands, children enter elementary school at the age of four. After 2 years of kindergarten (or the equivalent of 1 year of preschool and 1 year of kindergarten), formal reading and writing instruction is initiated. The children were followed from the Dutch equivalents of first through sixth grades and tested half-way through each grade. In grades 1, 3, and 5, the children's levels of word decoding and listening comprehension were assessed. In grades 2, 4, and 6, their reading comprehension achievement levels were taken. First of all, the study sought to determine to what extent the scores of L1 and L2 learners would differ over the grades. In addition, the cross-lagged effects between the criterion and predictor variables were examined in the early grades (i.e., grade 1 and 2), the intermediate grades (i.e., grade 3 and 4) and the upper grades (i.e., grade 5 and 6) by using structural equation modeling. Moreover, an attempt was made to find the best fitting structural model explaining the relationships between word decoding, listening comprehension, and reading comprehension for L1 and L2 learners throughout the grades.

Our first prediction was that in comparison with their native language speaking peers, L2 learners would be behind in listening comprehension and reading comprehension, far more than in word decoding. Furthermore, we predicted that the Simple View of Reading would equally apply to L1 and L2 learners. For the two groups of learners, it was hypothesized that in the early grades, word decoding and listening comprehension would predict reading comprehension more or less to the same extent, and that in subsequent grades listening comprehension would become the most dominant predictor.

\section{Method}

\section{Participants}

A randomly selected representative sample of 1,687 children from 72 urban elementary schools in The Netherlands was selected for inclusion in the present study prior to the 
children's school entry. All schools were had mixed ethnic lower middle-class school populations with children from predominantly lower SES families. The mean age upon initial measurement was 6 years and 8 months $(6 ; 8)$. The sample included a subsample of 1,293 children (631 boys and 662 girls) who learned Dutch as a native language and 394 children (202 boys and 192 girls) who learned Dutch as L2. Two-thirds of the children in the latter group originated from Mediterranean countries (Turkey, Morocco), and one-third came from previous Dutch colonies (Surinam and the Dutch Antilles). Given the fact that L1 and L2 learners came from the same schools, the SES levels of the two groups of children can be considered highly comparable.

The instructional conditions for the children were highly similar in that the same first-grade reading program was used by almost all of the schools, namely Veilig Leren Lezen (Learning to Read Safely). While this first-grade reading program is largely phonics based, the entire language experience is nevertheless emphasized. In the subsequent grades, word decoding skills were taught via the teaching of explicit word attack skills, text comprehension strategies were taught, and book reading activities were implemented. Increasingly complex and more varied texts were offered to the children to add new skills to their repertoires and thereby increase their reading fluency.

\section{Procedure}

In a longitudinal design, data on word decoding speed and listening comprehension, were collected half-way through grades 1, 3, and 5; and data on reading comprehension were collected half-way through grades 2,4 , and 6 (see Table 1).

Three word decoding tests were administered individually by a group of 24 welltrained graduate students outside the classroom on a total of six consecutive measurement occasions (see Table 1). In a 10-min session, the tests were presented to the children in a random order and scored online for accuracy. For control purposes, $10 \%$ of the children's performance was recorded for each individual experimenter. The inter-rater reliability was found to be greater than .97 in all cases. The tests of listening comprehension and reading comprehension were all administered by the experimenter on a class basis.

\section{Materials}

All of the tests used in the present study were selected from a battery of standardized tests constructed by the Dutch National Institute for Educational

Table 1 Tests used in different grades

\begin{tabular}{|c|c|c|c|}
\hline & $\begin{array}{l}\text { Word } \\
\text { decoding }\end{array}$ & $\begin{array}{l}\text { Listening } \\
\text { comprehension }\end{array}$ & $\begin{array}{l}\text { Reading } \\
\text { comprehension }\end{array}$ \\
\hline Grade 1 & WD1 & $\mathrm{LC} 1$ & \\
\hline Grade 2 & & & $\mathrm{RC} 2$ \\
\hline Grade 3 & WD3 & LC3 & \\
\hline Grade 4 & & & $\mathrm{RC} 4$ \\
\hline Grade 5 & WD5 & LC5 & \\
\hline Grade 6 & & & RC6 \\
\hline
\end{tabular}


Measurement (Gillijns \& Verhoeven, 1992). The tests had sufficient reliability. In all cases, the Cronbach's alphas were greater than .85. The listening comprehension and reading comprehension test items also yielded clearly unidimensional scales in terms of the on-parameter-maximum-likelihood analyses of Verhelst and Eggen (1989), which means that the scale scores for these tests can be reported.

The word decoding tests involved measures of the speed with which three types of words were read: monosyllabic CVC words, monosyllabic words with consonant clusters, and polysyllabic words (Verhoeven, 1991). For each type of word, a card containing 150 content words was constructed. All of the stimulus words were taken from a list of the 7,000 most frequently used Dutch words that teachers judge to be familiar to 6-year-old children in an oral context (Schaerlaekens, Kohnstamm, \& Lejaegere, 1999). This was done to ensure meaningfulness for the children. The words were printed in rows and, for each card, the child was asked to read the words as accurately and rapidly as possible. A time limit of 1 min was imposed for each list. In order to prevent repetition effects, the order of word presentation was varied from one occasion to the next. For each child, the total number of words read aloud and the total number of errors per card were recorded. The total number of words read correctly aloud per minute per card was then calculated as a general index of the child's word decoding ability per word type. For each child, a composite word decoding measure was also computed by summing up scores for the three word cards.

The listening comprehension test involved assessment of such higher-level processes as the monitoring of comprehension and drawing of inferences while listening to a text (Krom, 1992). The children first listened to a number of audiotaped short stories, interviews, and conversations. Thereafter, they were asked to answer orally presented questions in a multiple-choice format presented in a booklet. The test had no time limit, and the items formed unidimensional scales, which meant that scale scores could be computed for each child on each measurement occasion.

Reading comprehension was measured by two highly similar standardized tests that required the children to read a series of written texts and answer five questions addressing explicit and implicit meaning relations between the sentences in the text following the reading of each text. The first reading comprehension test consisted of simple text passages and was administered in grade 2, and the second reading comprehension test had more complex text passages and was administered in grade 4 and grade 6 . The items of the two tests were found to constitute unidimensional scales, which meant that scale scores could be computed for each child on each measurement occasion.

\section{Analyses}

Analyses of variance with repeated measures were undertaken to examine the development of word decoding, listening comprehension, and reading comprehension across grades. The partial $\eta^{2}$ or, in other words, proportion of the variance explained by the factor after correction for the other factors in the design was then computed as a measure of effect size for the factor Grade and the factor Group. 
In addition, a series of LISREL analyses (Version VIII, Jöreskog \& Sörbom, 1996) was conducted to explore the relations between the children's word decoding, listening comprehension, and reading comprehension skills over time. First, we examined the contributions of word decoding and listening comprehension to the prediction of reading comprehension in grades 2,4 , and 6 , respectively. It was also tested whether these predictions differ for L1 and L2 learners. In addition, crosssectional and longitudinal effects were included in the structural model designed to explain the variation in the development of the children's word decoding, vocabulary, listening comprehension, and reading development. The relevant estimates and tests of significance were calculated using maximum likelihood analysis. The fit of the model was then evaluated via Chi-square analyses and various goodness of fit indices: GFI (goodness of fit index), AGFI (adjusted goodness of fit index), NFI (normed fit index), and RMSEA (root mean square error of approximation). According to both Jaccard and Wan (1996) and Hu and Bentler (1999), the Chi-square statistics cannot be considered decisive since the significance of a Chi-square test also depends on sample size, but that the fit of a model is satisfactory when the GFI, AGFI, and NFI are greater than .90 and the RMSEA is lower than .08.

\section{Results}

Descriptives as a function of grade level and group

In Table 2, the means and standard deviations for the tests of word decoding, listening comprehension, and reading comprehension are presented as a function of Grade.

For word decoding, the repeated measures analysis of variance with Grade and Group as factors yielded a significant main effect of Grade, $F(2,1,684)=$ $13,153.35, p<.001$ with a partial $\eta^{2}$ of .94 , a non-significant main effect of Group, $F(1,1,685)=.905, p=.34$ with a partial $\eta^{2}$ of .001 , and significant Grade $\mathrm{x}$ Group interaction, $F(2,1,684)=5.496, p<.01$ with a partial $\eta^{2}$ of .006 . The differences in word decoding scores tended to diminish over the grades. At the final moment of measurement (grade 5), the differences in word decoding between L1 and L2 learners were indeed no longer significant, $t(1,1,685)=-.050, p=.96$.

For listening comprehension, the repeated measures analyses of variance with Grade and Group as factors showed a significant main effect of Grade, $F(2$, $1,684)=5,955.21, p<.001$ with a partial $\eta^{2}$ of. 88 , a significant main effect of Group, $F(1,1,685)=482.43, p<.001$ with a partial $\eta^{2}$ of .22 , and non-significant Grade $x$ Group interaction, $F(2,1,684)=1.73, p=.178$ with a partial $\eta^{2}$ of .002 . Although the differences in listening comprehension tend to become smaller over the grades, they remain significant in grade 5 .

For reading comprehension, the test for grade 2 differed from the one in grade 4 and 6 . In grade 2, the difference between first and second language learners was found to be significant, $t(1,1,685)=14.92, p<.001)$. In subsequent grades, a significant main effect of Grade was found, $F(1,1,685)=5,845.34, p<.001$ with a 
Table 2 Means and standard deviation for measures of word decoding, listening comprehension, and reading comprehension as a function of grade

\begin{tabular}{|c|c|c|c|c|c|c|}
\hline & \multicolumn{2}{|l|}{ Word decoding } & \multicolumn{2}{|c|}{ Listening comprehension } & \multicolumn{2}{|c|}{ Reading comprehension } \\
\hline & L1 & L2 & $\mathrm{L} 1$ & $\mathrm{~L} 2$ & $\mathrm{~L} 1$ & $\mathrm{~L} 2$ \\
\hline Grade 1 & $56.30(39.83)$ & $54.42(35.39)$ & $102.30(4.88)$ & $95.38(5.97)$ & & \\
\hline Grade 2 & & & & & $100.08(5.85)$ & $95.08(5.75)$ \\
\hline Grade 3 & $214.19(55.06)$ & $208.85(56.40)$ & $108.66(5.86)$ & $102.04(6.19)$ & & \\
\hline Grade 4 & & & & & $-.018(.19)$ & $-.169(.18)$ \\
\hline Grade 5 & $274.08(52.13)$ & $274.58(53.77)$ & $117.96(6.63)$ & $111.02(6.65)$ & & \\
\hline Grade 6 & & & & & $.228(.16)$ & $.117(.15)$ \\
\hline
\end{tabular}

partial $\eta^{2}$ of .78, a significant main effect of Group, $F(1,1,685)=202.46, p<.001$ with a partial $\eta^{2}$ of .11, and significant Grade $\mathrm{x}$ Group interaction, $F(1$, $1,685)=32.19, p<.05$ with a partial $\eta^{2}$ of .02 . The latter interaction shows that the differences in reading comprehension tend to be smaller with progression of grade.

Word decoding and listening comprehension as predictors of reading comprehension

In order to explore the contribution of word decoding and listening comprehension as predictors of reading comprehension, linear structural models were computed separately for the early grades (1-2), the intermediate grades (3-4), and the upper grades (5-6). In Fig. 1, the results are presented.

In the early grades, reading comprehension was substantially predicted by both word decoding and listening comprehension. The proportion of variance of reading comprehension explained was .61. The same model equally applied to first and

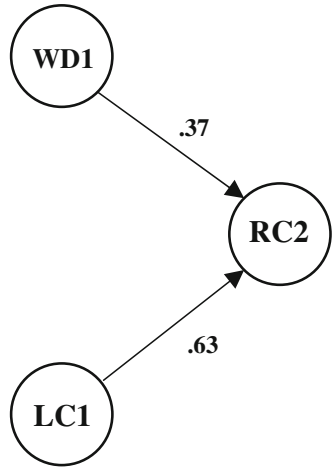

(a)

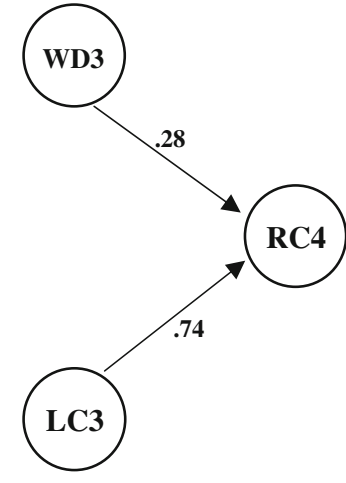

(b)

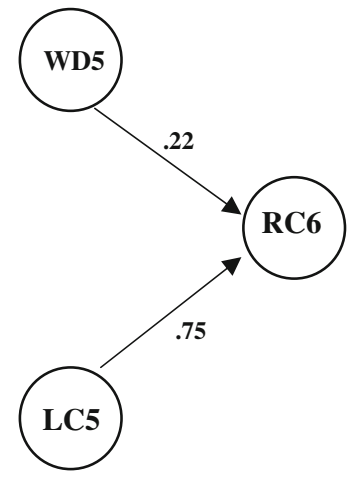

(c)

Fig. 1 Trivariate cross-lagged associations between word decoding (WD), listening comprehension (LC), and reading comprehension (RC) in grades 1-2 (a), grades 3-4 (b) and grades 5-6 (c) 
second language learners, $\chi^{2}(2)=.73, p=.69$. In the intermediate grades, listening comprehension was a much stronger predictor of reading comprehension than word decoding. The proportion of variance of reading comprehension explained was .77 . Again, the same model equally applied to first and second language learners, $\chi^{2}(2)=4.38, p=.11$. In the upper grades, listening comprehension was found to be even more important in predicting children's reading comprehension scores. Word decoding and listening comprehension explained about 70 percent of the variance in reading comprehension with no differences found between first and second language learners, $\chi^{2}(2)=2.71, p=.26$.

Finally, a longitudinal model predicting children's reading comprehension development from word decoding and listening comprehension throughout the grades was tested. For all participants, the fit of this model is satisfactory: $\chi^{2}(9)=45.941, p=.000, G F I=.994, A G F I=.970, N F I=.998, R M S E A=$ .049. To test the difference between L1 and L2 readers, two simultaneous models were estimated, one without and one with equality restrictions on the regression coefficients. For the model without restrictions $\chi^{2}(18)=40.783, p<.01$, $R M S E A=.039$. For the model with equality restrictions $\chi^{2}(34)=65.654$, $p<.001, R M S E A=.033$. The difference between the two models showed a tendency to be significant $(p=.07)$. The common metric standardized solutions in the unrestricted model are represented for the L1- and L2-readers, in Fig. 2.

For L1 learners, the proportions explained variance for RC2, RC4 and RC6 were $.53, .76$ and .78 , respectively. For L2 learners, the proportions variance explained for RC2, RC4 and RC6 were .64, .74 and .76, respectively. The two structural models appear to be highly comparable. First grade WD substantially influences second grade RC, third grade WD slightly influences fourth grade $\mathrm{RC}$, and fifth grade WD slightly influences sixth grade RC. First grade LC strongly influences second grade RC. In subsequent grades, reciprocal relations between LC and RC are evidenced, which shows the development of the two skills to be highly interdependent. However, the relationship between listening comprehension and reading comprehension is reciprocal in the $\mathrm{L} 1$ group to a greater extent than in the L2 group.

\section{Conclusions and discussion}

Several conclusions can be drawn from the present study. To begin with, the data make it clear that throughout the primary grades children make substantial progress in their listening comprehension, word decoding, and reading comprehension. It is also clear that children learning to read in a second language have difficulty in attaining the same levels of all of these skills as compared with their native language speaking peers. However, over the years, the differences in word decoding skills tend to disappear. For listening comprehension and reading comprehension, the differences become smaller but remain significant in the upper grades. This result corresponds to the findings of earlier cross-linguistic studies comparing the literacy development of L1 and L2 learners (see Droop \& Verhoeven, 2003; Lesaux \& Koda, 2006; Verhoeven, 2010). 


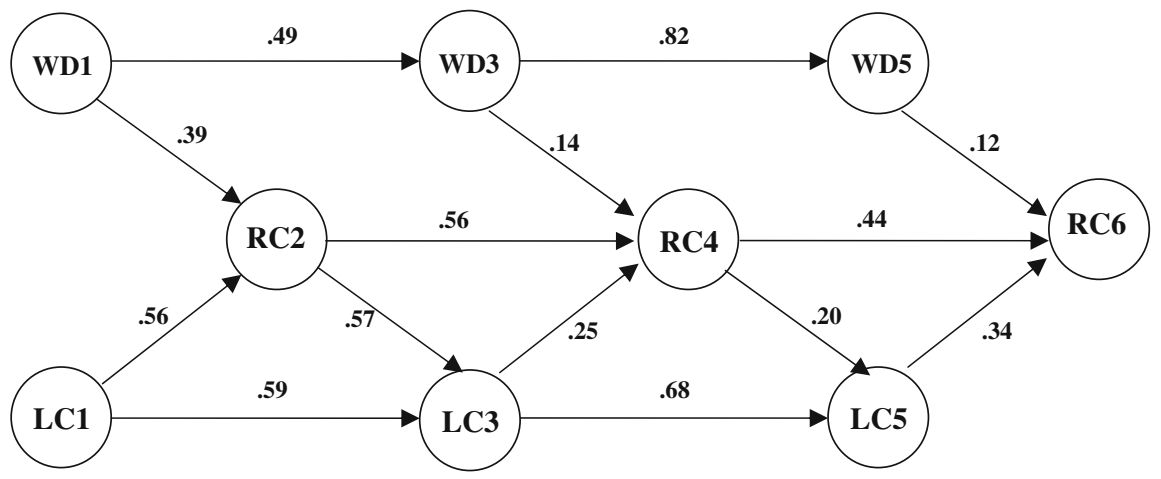

(a)

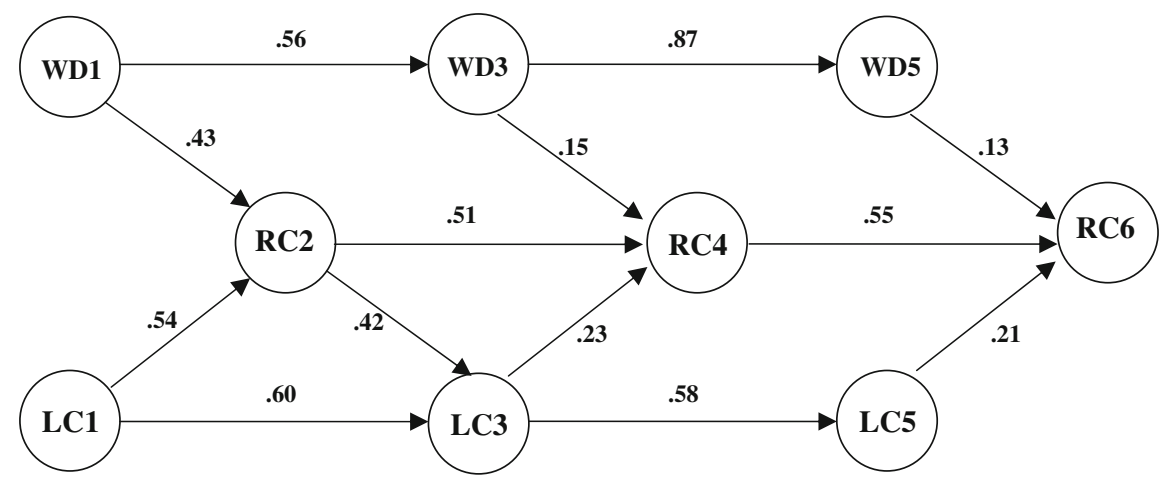

(b)

Fig. 2 Trivariate cross-lagged associations $(p<.01)$ between word decoding (WD), listening comprehension (LC), and reading comprehension (RC) for L1 learners (a) and L2 learners (b)

Furthermore, the present study provides evidence of the fact that the reading comprehension achievement of L1 and L2 learners can to a high extent be predicted from their listening comprehension and word decoding abilities. In the lower grades, $61 \%$ of the variance in reading comprehension could be explained from these two variables, and in the intermediate and upper grades the amount of explained variance even went up to $70 \%$. Our data on the prediction of reading comprehension at different grade levels clearly shows that starting from the intermediate grades, the predictive power of word decoding tends to diminish at favor of a greater impact of listening comprehension. For word decoding, our data show a substantial influence of first grade skill on second grade reading comprehension and a small influence of fifth grade skill on sixth grade reading comprehension. In other research, substantial effects of word decoding on reading comprehension have been reported for the intermediate elementary grade levels and/or higher elementary grade levels (e.g., Goff, Pratt, \& Ong, 2005). However, this may be due to the fact that in the vast majority of cases the reading of English was involved which can be regarded a highly opaque orthography (Share, 2008). It has indeed been found that in a more 
transparent orthography like Dutch the individual variation in word decoding skills among both first language and second learners tend to level off over the years (cf. Verhoeven \& van Leeuwe, 2009, 2011).

The longitudinal data collected throughout the primary grades shows some additional findings of interest. First, for each of the linguistic variables, significant progress from one grade to the next was consistently encountered. The present data thus provide empirical support for the proposition that reading development should be conceptualized as a continuum (Logan, 1997). Second, the stability of the individual differences observed in the children's word decoding, listening comprehension, and reading comprehension throughout the school years was quite high. In other words, our data show the individual differences that occur at the very beginning of reading instruction to prevail across grades. This result is keeping with the results of other studies showing strong longitudinal effects in the development of reading (cf. de Jong \& van der Leij, 2002; Oakhill, Cain, \& Bryant, 2003; Torgeson, Wagner, Rashotte, Burgess, \& Hecht, 1997).

The present data are also in support of Hoover and Gough's Simple View of Reading. The development of reading comprehension is closely related to the development of not only word decoding skills but also the development of listening comprehension skills. While word decoding predicted reading comprehension across the different grade levels, the picture looked more complicated for listening comprehension. During the start of literacy instruction, reading comprehension is clearly predicted by the level of listening comprehension skill acquired during the preschool years. In subsequent grades, however, the associations go in both directions and are often, but not always, reciprocal. This finding is in line with the results of an earlier study by Sears and Keogh (1993). Apparently, listening comprehension and later reading comprehension are so intricately intertwined that progress on one variable more or less automatically promotes progress on the other (see also Perfetti et al., 2005).

It is interesting to note that the longitudinal data analysis bears to light strong similarities in the Simple View of Reading perspective for L1 and L2 learners. In both groups of learners reading comprehension appears to be highly dependent on their oral language skills, especially as word decoding becomes more automated. The only difference found in the present study is that the reciprocity of the relationship between listening comprehension and reading comprehension is stronger in the L1 group as compared with the L2 group. It can tentatively be concluded that for the L2 learners, reading comprehension development is more strictly dependent on their oral language proficiency as compared to L1 learners which is in line with earlier findings from Droop and Verhoeven (2003).

The results of the present study have some clear practical implications. The findings make it clear that as children develop better word-decoding skills, their reading comprehension becomes more constrained by their listening comprehension skills. Nevertheless, for even children in the highest elementary grades, the association between word decoding and reading comprehension prevails. Thus efficient decoding of word forms appears to constitute a necessary condition for reading comprehension. In fact, a child's word identification skill appears to set the limits on reading comprehension during the early stages of reading development. 
Continued attention to the speed and automaticity of word decoding and lexical access throughout the elementary school years can thus be recommended for both L1 and L2 learners. Given the close relationship between listening comprehension and reading comprehension, special attention should also be devoted to the structure of texts to facilitate the further development of children's comprehension skills in both the oral and written modality. Because of the fact that L2 learners start out literacy instruction from a disadvantaged position in oral comprehension, continued attention to their L2 oral proficiency can be seen as highly important. Besides, reading comprehension strategies should be highlighted in the classroom. Children's instruction should therefore focus on the identification of signal words, topic sentences, and other organizational structures that can help readers determine the main ideas in a text and the most important relations between the various components of a piece of text (Dickson, Simmons, \& Kameenui, 1995).

Open Access This article is distributed under the terms of the Creative Commons Attribution Noncommercial License which permits any noncommercial use, distribution, and reproduction in any medium, provided the original author(s) and source are credited.

\section{References}

Bast, J., \& Reitsma, P. (1998). Analyzing the development of individual differences in terms of Matthew effects in reading: Results from a Dutch longitudinal study. Developmental Psychology, 34, 1373-1399.

Bernhardt, E. B. (2005). Progress and procrastination in second-language reading. In M. McGroarty (Ed.), Annual review of applied linguistics (pp. 133-150). Cambridge, MA: Cambridge University Press.

Cain, K., \& Oakhill, J. (1998). Comprehension skill and inference-making ability: Issues of causality. In C. Hulme \& R. M. Joshi (Eds.), Reading and spelling (pp. 343-367). Hillsdale, NJ: Erlbaum.

Carver, R. P. (1993). Merging the simple view of reading with rauding theory. Journal of Reading Behavior, 25, 439-455.

Chen, R. S., \& Vellutino, F. R. (1997). Prediction of reading ability: A cross-validation study of the simple view of reading. Journal of Literacy Research, 29, 1-24.

de Jong, P., \& van der Leij, A. (2002). Effects of phonological abilities and linguistic comprehension on the development of reading. Scientific Studies of Reading, 6, 51-77.

Deacon, S. H., Wade-Woolley, L., \& Kirby, J. R. (2009). Flexibility in young second-language learners: Examining the language specificity of orthographic processing. Journal of Research in Reading, 32, 215-229.

Dickson, S. V., Simmons, D. C., \& Kameenui, E. J. (1995). Text organization: Curricular and instructional implications for diverse learners (Technical Report No. 18). Eugene, OR: National Center to Improve the Tools of Education.

Droop, M., \& Verhoeven, L. (2003). Language proficiency and reading ability in first- and secondlanguage learners. Reading Research Quarterly, 38, 78-103.

Ellis, N. C., \& Schmidt, R. (1997). Morphology and longer distance dependencies: Laboratory research illuminating the A in SLA. Studies in Second Language Acquisition, 19, 145-171.

Genesee, F., Lindholm-Leary, K., Saunders, W., \& Christian, D. (2006). Educating English language learners: A synthesis of research evidence. New York, NY: Cambridge University Press.

Geva, E., \& Siegel, L. S. (2000). Orthographic and cognitive factors in the concurrent development of basic reading skills in two languages. Reading and Writing: An Interdisciplinary Journal, 12, 1-30.

Gillijns, P., \& Verhoeven, L. (1992). Het CITO leerlingvolgsysteem: Met het oog op de praktijk [The CITO pupil monitoring system: Focus on practice]. Pedagogische Studiën, 69, 291-296.

Goff, D., Pratt, C., \& Ong, B. (2005). The relations between children's reading comprehension, working memory, language skills and components of reading decoding in a normal sample. Reading and Writing: An Interdisciplinary Journal, 18, 583-616. 
Goldman, S. R. (2003). Learning in complex domains: When and why do multiple representations help? Learning and Instruction, 13, 239-244.

Hoover, W. A., \& Gough, P. B. (1990). The simple view of reading. Reading and Writing: An Interdisciplinary Journal, 2, 127-160.

Hu, L. T., \& Bentler, P. M. (1999). Cutoff criteria for fit indexes in covariance structure analysis: Conventional criteria versus new alternatives. Structural Equation Modeling, 6, 1-55.

Jaccard, J., \& Wan, C. K. (1996). LISREL approaches to interaction effects in multiple regression. Thousand Oaks, CA: Sage.

Jöreskog, K. G., \& Sörbom, D. (1996). LISREL 8. User's reference guide. Chicago, IL: Scientific Software International, Inc.

Juel, C. (1988). Learning to read and write: A longitudinal study of 54 children from first through fourth grades. Journal of Educational Psychology, 80, 437-447.

Kitajima, R. (1997). Referential strategy training for reading comprehension of Japanese texts. Foreign Language Annals, 30, 84-97.

Krom, R. (1992). Toetsen begrijpend luisteren [Test for listening comprehension]. Arnhem, The Netherlands: National Institute for Educational Measurement.

Lesaux, N., \& Koda, K. (2006). Development of literacy. In D. August \& T. Shanahan (Eds.), Report of the National Literacy Panel on K-12 youth and adolescents (pp. 75-122). Mahwah, NJ: Lawrence Erlbaum.

Lindsey, K. A., Manis, F. R., \& Bailey, C. E. (2003). Prediction of first-grade reading in Spanish-speaking English-learners. Journal of Educational Psychology, 95, 482-494.

Logan, G. D. (1997). Automaticity and reading: Perspectives from the instance theory of automatization. Reading and Writing Quarterly, 13, 123-146.

Lopez, L. M., \& Greenfield, D. B. (2004). The cross-language transfer of phonological skills of Hispanic head start children. Bilingual Research Journal, 28, 1-18.

National Reading Panel. (2000). Teaching children to read: An evidence-based assessment of the scientific research literature on reading and its implications for reading instruction. Washington, DC: The National Institute of Child Health and Human Development.

Oakhill, J., Cain, K., \& Bryant, P. E. (2003). The dissociation of word reading and text comprehension: Evidence from component skills. Language and Cognitive Processes, 18, 443-468.

Perfetti, C. A. (1998). Two basic questions about reading and learning to read. In P. Reitsma \& L. Verhoeven (Eds.), Problems and interventions in literacy development (pp. 15-48). Dordrecht, The Netherlands: Kluwer.

Perfetti, C. A., Landi, N., \& Oakhill, J. (2005). The acquisition of reading comprehension skill. In M. J. Snowling \& C. Hulme (Eds.), The science of reading: A handbook (pp. 227-247). Oxford, UK: Basil Blackwell.

Proctor, C. P., Carlo, M., August, D., \& Snow, C. E. (2005). Native Spanish-speaking children reading in English: Toward a model of comprehension. Journal of Educational Psychology, 97, 246-256.

Schaerlaekens, A., Kohnstamm, D., \& Lejaegere, M. (1999). Streeflijst woordenschat voor zesjarigen [Word frequency list for Dutch 6-year-olds]. Lisse, The Netherlands: Swets \& Zeitlinger.

Sears, S., \& Keogh, B. (1993). Predicting reading performance using the Slingerland procedures. Annals of Dyslexia, 43, 78-89.

Share, D. (2008). On the Anglocentricities of current reading research and practice: The perils of overreliance on an "outlier" orthography. Psychological Bulletin, 134, 584-615.

Siegel, L. (2003). Bilingualism and reading. In L. Verhoeven, C. Elbro, \& P. Reitsma (Eds.), Precursors of functional literacy (pp. 287-302). Amsterdam, The Netherlands: John Benjamins.

Torgeson, J. K., Wagner, R. K., Rashotte, C. A., Burgess, S., \& Hecht, S. (1997). Contributions of phonological awareness and rapid automatic naming ability to the growth of word-reading skills in second-to fifth-grade children. Scientific Studies of Reading, 1, 161-195.

Tunmer, W., \& Hoover, W. (1993). Components of variance models of language-related factors in reading disability: A conceptual overview. In R. J. Joshi \& C. K. Leong (Eds.), Reading disabilities: Diagnosis and component processes (pp. 135-173). Dordrecht, The Netherlands: Kluwer.

Vauras, M., Kinnunen, R., \& Kuusela, L. (1994). Development of learning strategies in high-, averageand low-achieving primary school children. Journal of Reading Behavior, 26, 361-389.

Verhelst, N., \& Eggen, T. (1989). Psychometrische en statistische aspecten van peilingsonderzoek [Psychometric and statistical aspects of national assessment studies]. PPON Report No 4. Arnhem, The Netherlands: Cito. 
Verhoeven, L. (1990). Acquisition of reading in a second language. Reading Research Quarterly, 25, 90-114.

Verhoeven, L. (1991). Drie-minuten-toets [Word decoding test]. Arnhem, The Netherlands: Cito.

Verhoeven, L. (2000). Components in early second language reading and spelling. Scientific Studies of Reading, 4, 313-330.

Verhoeven, L. (2010). Second language reading acquisition. In M. L. Kamil, P. D. Pearson, E. B. Moje, \& P. Afflerbach (Eds.), Handbook of reading research (pp. 661-683). New York: Taylor \& Francis.

Verhoeven, L., \& Perfetti, C. (2008). Advances in text comprehension: Model, process and development. Applied Cognitive Psychology, 22, 293-301.

Verhoeven, L., \& van Leeuwe, J. (2009). Modeling the growth of word decoding skills: Evidence from Dutch. Scientific Studies of Reading, 13, 205-223.

Verhoeven, L., \& van Leeuwe, J. (2011). Role of gender and linguistic diversity in word decoding development. Learning and Individual Differences, 21, 359-367.

Vermeer, A. (2001). Breadth and depth of vocabulary in relation to L1/L2 acquisition and frequency of input. Applied Psycholinguistics, 22, 217-234.

Yuill, N., \& Oakhill, J. (1991). Children's problems in text comprehension: An experimental investigation. Cambridge, UK: Cambridge University Press. 